Atıf İçin: Alıcı H, 2021. HnRNPA2'in LC(286-291) Domain Fibrili ve Onun D290V Mutasyonu Hakkında Teorik Bir Çalışma. Iğdır Üniversitesi Fen Bilimleri Enstitüsü Dergisi, 11(2): 1080-1089.

To Cite: Alıc1 H, 2021. A Theorotical Study About LC(286-291) Domain of hnRNPA2 and its D290V Mutation. Journal of the Institute of Science and Technology, 11(2): 1080-1089.

\title{
HnRNPA2'in LC(286-291) Domain Fibrili ve Onun D290V Mutasyonu Hakkında Teorik Bir Çalışma
}

\section{Hakan ALICI ${ }^{1 *}$}

ÖZET: Son zamanlarda, hnRNPA'lerin işlevindeki bozukluklar başta amiyotrofik lateral skleroz (ALS) ve frontotemporal demans (FTD) olmak üzere birçok nörodejeneratif hastalıklar ile ilişkilendirilmektedir. hnRNPA'lerin düşük karmaşıklık (LC) domainlerinin fibrilleşme eğilimlerinin bu işlev bozukluklarının temel nedeni olduğu düşünülmektedir. Bu çalışmada atomik yapısı çok yakın zamanda ortaya konulmuş D290V mutasyonuna sahip hnRNPA2'nin LC(286-291) fibril domaininin bir polimorfu (pdb kod:6WPQ) ve bu poliformun mutasyonsuz yani vahşi tip (WT) fibril formu hakkında bir moleküler Dinamik (MD) simülasyon çalışması sunuyoruz. MD simulasyon sonuçlarına göre önerilen fibril polimorf yapısı için D290V mutasyonun kararlı bir konformasyona sahip olduğu ancak onun WT formun bu fibril polimorf yapı konformasyonu için kararsız olduğu tespit edilmiştir. Sonuç olarak çalışmada elde edilen bulgular gelecekteki muhtemel ilaç çalışmaları için yalnızca D290V fibril yapısının hedef yapı olarak ele alınabileceğini işaret etmektedir.

Anahtar Kelimeler: Düşük karmaşıklık alanı, moleküler dinamik, simülasyon, D290V

\section{A Theorotical Study bout LC(286-291) Domain of hnRNPA2 and its D290V Mutation}

ABSTRACT: Recently, disorders in the function of hnRNPAs have been associated with many neurodegenerative diseases, especially amyotrophic lateral sclerosis (ALS) and frontotemporal dementia (FTD). In addition, the fibrillation tendency of the low complexity (LC) domains of hnRNPAs is thought to be the root cause of these dysfunctions. In this paper, we present a molecular dynamic (MD) simulation study for the recently crystalized a fibril polymorph of the LC (286-291) domain (pdb id:6WPQ) of hnRNPA2 with the D290V mutation and its wild-type (WT) fibril form, that is no mutation. According to the MD simulation results, it was detected that fibril polymorph with D290V mutation has stable conformations, but WT is unstable for this fibril polymorph. As a result, the findings of the study indicate that only the D290V fibril structure can be considered as the target structure for possible future drug studies.

Keywords: Low complexity domain, molecular dynamic, simulation, D290V

\footnotetext{
${ }^{1}$ Hakan ALICI (Orcid ID: 0000-0001-5105-8331), Zonguldak Bülent Ecevit Üniversitesi, Fen Edebiyat Fakültesi, Fizik Bölümü, Zonguldak, Türkiye

*Sorumlu Yazar/Corresponding Author: Hakan ALICI, e-mail: hakanalici@ beun.edu.tr
} 


\section{GİRiş}

Heterojen nükleer RNA (hnRNA) komplekslerinin bileşenlerinden biri olan hnRNPA2 proteini, RNA'nın stabilizasyonunda, bağlanmasında, translasyonunda ve nükleo-sitoplazmik taşınmada görev alır (Burd ve Dreyfuss 1994; Guil ve Cáceres 2007; White ve ark., 2008; Kato ve ark., 2012; JeanPhilippe ve ark., 2013; Kim ve ark., 2013; Jain ve ark., 2017; Amaya ve ark., 2018; Purice ve Taylor 2018). Ayrıca mesajcı RNA (mRNA)'ların korunmasında önemli işleve sahip olup, membransız organel (MLO) olarak adlandırılan sitoplazmik stres granüllerinin de bir bileşenidir (Kato ve ark., 2012; Gomes ve Shorter 2019).

HnRNPA2 341 adet aminoasite sahip olup yapısal olarak iki RNA tanıma motifi (RRM'ler), bir RNA bağlama alanı (RBD) ve C-terminal düşük karmaşıklık (LC) alanı olmak üzere dört domainden oluşmaktadır (Purice ve Taylor, 2018). HnRNPA'ın nükleo-sitoplazmik taşınmada veya dinamik faz ayrımında arızalanması, anormal amiloid toplanmasına ve nörodejenerasyona yol açmaktadır. HnRNPA'in LC alanının ise hem dinamik sıvı-sıvı faz ayrışmasını hem de amiloid fibril toplanmasını (Kim ve ark., 2013; Molliex ve ark., 2015; Xiang ve ark., 2015; Duan ve ark., 2019; Gui ve ark., 2019) yönlendirdiği düşünülmektedir. Ayrıca hnRNPA2'ın hem hücresel stres altında hem de nörodejeneratif koşullarda mutasyona uğramış formda fibril yapıları oluşturdukları da bilinmektedir (Gilks ve ark., 2004; Kim ve ark., 2013). Ancak bu hastalık mutasyonlarının atomik düzeyde fibril agregalarının polimorfları üzerinde nasıl yapısal değişime neden olduğu hakkında çok az şey bilinmektedir. Sahada yapılan tüm deneysel çabalara rağmen, agregaların amorf halde olmalarından dolayı standart protokoller kullanılarak bu polimorfların atomik düzeyde mikroskobik ayrıntılarla karakterize edilmesini zorlaştırmaktadır. Bundan dolayı protein yapı ve özelliklerini moleküler seviyede araştırmak için yaygın olarak kullanılan başlıca alternatif stratejiler arasında, bilgisayar simülasyonları giderek artan bir öneme sahiptir.

Bu çalışmada atomik yapısı çok yeni olarak çözülmüş olan hnRNPA2'nın LC domaininin 286291 aminoasit dizilimini içeren bir fibril segment polimorf yapısını ele aldık (Pdb kod: 6WPQ (Lu ve ark., 2020)). Bu fibril segmenti D290V mutasyonunu içermektedir ve dolayısıyla bu fibril agrega konformasyonun bu mutasyona sahip hastalar için muhtemel tedavi edici ilaç molekülleri için hedef fibril yapıları olarak ele alınması muhtemeldir. Ancak buna ilaveten bu fibril polimorfunun mutasyonsuz vahşi (doğal) tip yapısının benzer konformasyonel formda bulunup bulunamayacağını tespit etmek D290V için tasarlanması muhtemel ilaç moleküllerinin vahşi tip içinde kullanılıp kullanılamayacağını gösterebilir.

$\mathrm{Bu}$ bağlamda bu çalışmanın başlıca amacı Moleküler Dinamik (MD) simülasyon yöntemi kullanarak vahşi tip ve D290V mutasyonuna sahip hnRNPA2'nın LC(286-291) domain fibril segmentlerininin konformasyonel yapı özelliklerini ve onların kararlılıklarını araştırmaktır. Bu amaç doğrultusunda çalışmada elde edilen bulgulara göre vahşi tipin bahsi geçen fibril formunda bulunamayacağı dolaysıyla gelecekteki ilaç geliştirme çalışmalarında yalnızca D290V mutasyonlu fibril yapısının ele alınabileceği sonucuna varılmıştır.

\section{MATERYAL VE METOT}

Sunulan çalışmadaki LC(286-291) domain fibril kesitinin 3B (üç boyutlu) yapısı için Protein Data Bank (PDB)' a 6WPQ kodu ile depo edilmiş olan X-ray kristal yapısı kullanılmıştır (Lu ve ark., 2020). $\mathrm{Bu}$ kristal yapısının 290. aminoasidi D290V hastalık mutasyonunu içermektedir. Çalışmamızda mutasyonlu yapı ile kıyaslama yapabilmek için bu fibril kesitinin mutasyonsuz vahşi tip fibril kesiti PyMOL (DeLano, 2002) programı kullanılarak elde edilmiş ve bu sistem çalışmamızda "WT" olarak 
adlandırılmıştır. Bahsi geçen fibril polimorf sistemleri karşılıklı yerleştirilmiş iki adet protofilament yaprağından oluşmakta olup her bir yaprak tabakası da düzenli olarak üst üste istiflenmiş beş LC(286291) domain ipliğine sahiptir. MD simülasyonlarına başlangıç yapısı olarak kullanılan D290V ve WT sistemlerinin 3B yapıları Şekil 1'de sunulmuştur. Şekilde yapıların aminoasit dizilimleri ve çalışmamızda yaprakların ve ipliklerin ele alındığı şekliyle adlandırılışları ayrıntılı olarak verilmiş̧ir.

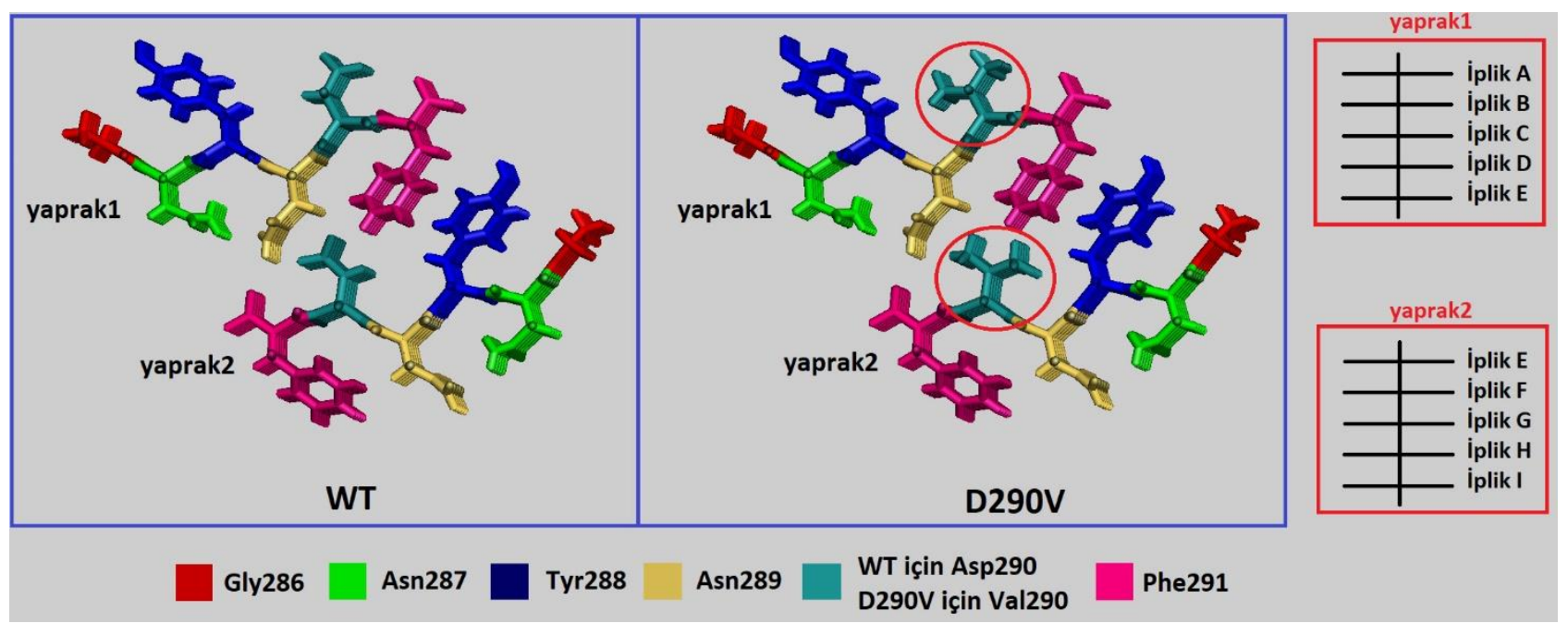

Şekil 1. hnRNPA2'nın LC(286-291) domain WT fibrili ve onun D290V mutasyonlu fibril yapılarının konformasyonlarının 3B'lu görselleştirmesi

MD simülasyon çalışmaları GROMACS programı (Abraham ve ark., 2015) ile gerçekleştirilmiştir. Simülasyonlarda atomik etkileşimleri tanımlayabilmek için CHARMM36 enerji fonksiyonu (Huang ve ark., 2017) ve TIP3P çözelti modeli (Jorgensen ve ark., 1983) kullanılmıştır. Şekilde verilen başlangıç yapılarının GROMACS' in pdb2gmx modülü kullanılarak hidrojen atomları önce silinmiş daha sonra CHARMM36'ya uygun olacak şekilde yeniden eklenmiştir. Daha sonra WT ve D290V sistemlerinin bu yapıları $6.5 \times 6.5 \times 6.5 \mathrm{~nm}$ boyutlarında kübik bir simülasyon kutusunun merkezine yerleştirilmiştir. Simulasyonlarda PBC (Periodic Boundary Coundition) kullanılmış olup PBC'nin gerçek olmayan bir atomik etkileşime sebebiyet vermemesi için simülasyon kutusu ile protein atomları arasındaki minimum uzaklık 1nm olarak ayarlanmıştır. Daha sonra simülasyon kutularına GROMACS'ın solute modülü kullanılarak 5246 adet su molekülü eklenmiştir. Ayrıca simülasyonlarda uzun erimli etkileşimleri tanımlayabilmek için PME (Particle Mesh Ewald) teorisi (Darden ve ark., 1993; Essmann ve ark., 1995) kullanılmış olup bu teori nötralize olmuş simülasyon sistemleri gerektirmektedir. D290V sistemi kendiliğinden nötralize iken -10 yüke sahip olan WT sistemine 10 adet Na+ iyonu eklenerek WT sistemi de nötralize edilmiştir. Daha sonra nötralize olmuş sistemlerdeki protein atomları arasındaki kötü temasları ve uygun olmayan geometrik yönelimlerini yok etmek için "Steepest Descent" metodu kullanılarak enerji minimizasyonu yapılmıştır. Sistemlerin enerji minimizasyonularının ardından ve gerçek (ürün) dinamik simülasyonlar öncesinde, çözelti atomlarının ve iyonların protein atomları etrafında gevşemesini sağlayabilmek adına iki aşamalı dengeleme dinamik simülasyonları yapılmıştır. $\mathrm{Bu}$ simülasyonların her biri 2ns simülasyon süresine sahip olup sirasiyla NVT ve NPT istatiksel topluluklarda gerçekleştirilmişlerdir. Dengeleme dinamik simülasyonları tamamlandıktan sonra deneysel koşullara en yakın istatiksel topluluk olan NPT'de 150ns'lik ürün dinamik simülasyonları gerçekleştirilmiştir. Dinamik simülasyonlarda sıcaklık v-rescale termostatı (Bussi ve ark., 2007) ile 310 K' de, basınç Parrinello-Rahman barostatı (Parrinello ve Rahman 1981) ile 1 bar da sabit tutulmuştur 
Ayrıca bilindiği gibi, MD simülasyonlarının sonuçlarının deterministtik olması beklenilir, bu nedenle güvenilir simülasyon bulguları için ilgilenilen sistem için yalnızca bir MD simülasyonunun çalıştırılması çok riskli sonuçlar ortaya çıkarılabilir. Bu nedenle, simülasyon sonuçlarının güvenilirliğini sağlamak için klasik MD simülasyonlarının farklı başlangıç koşullarında birden fazla kez tekrarlanması gerekliliği ortaya çıkmaktadır. Bu bağlamda WT ve D290V sistemlerinin her biri için faklı başlangıç hız dağılım setine sahip ikişer adet simülasyon oluşturulmuştur. Böylece, sistemlerin birden fazla bağımsız simülasyon çalışmasıyla, bulguların sadece bir simülasyon çalışmasıyla tesadüfen elde edilmediğini garanti etmiş olmaktayız.

Sunulan çalışmada grafiklerde sergilenen metrik analizlerin sonuçları, tüm sonuçların aynı skala üzerinde gözlemlenebilmesi için Log10 ölçeğinde çizdirilmiştir. Ayrıca. 3B görselleştirilmeler için PyMOL programı kullanılmıştır.

\section{BULGULAR VE TARTISSMA}

Çalışmada ele alınan fibril arayüz sistemlerinin konformasyonel kararlılığını araştırmak için ilk olarak RMSD (kök ortalama kare sapması: root mean square deviation) analizi gerçekleştirilmiştir. RMSD analizi protein konformasyonundaki atomların simülasyona başlamadan önceki yani doğal konumlarından simülasyonlar boyunca ne kadar uzaklaştığının bir göstergesidir. Başka bir deyişle RMSD analizi protein konformasyonundaki dinamik değişimleri takip etmeye imkân sağlamaktadır. WT ve D290V sistemlerine ait ikişer adet simülasyon için 150ns simülasyonlar boyunca RMSD değerleri Şekil 2'de verilmiştir. Şekil incelendiğinde her bir sistemin kendine ait simülasyon setlerinin benzer RMSD değer davranışına sahip olduğu açıkça gözlemlenmektedir. Bu durum simülasyonlar sonucunda elde edilen bulguların güvenilebilirliğini temin etmektedir. Log10 skalasında sergilenen RMSD değerlerinin değişimleri incelendiğinde WT sistemine ait simülasyonlar için elde edilen değerlerin özellikle 45ns'den sonra çok yüksek değerlere doğru gitmeye başladığını yaklaşık 140ns' den sonra ise $\sim 14 \mathrm{~nm}$ gibi aşırı derecede yükssek bir değere ulaşarak bu değerde sabit kaldığı gözlemlenmektedir. Literatürde bu türden yüksek ve değişken RMSD değerleri protein konformasyonlarındaki köklü değişimlere atfedilmektedir (Alıcı ve ark., 2018). Buna göre WT sistemin 10 adet düzenli istiflenmiş fibril ipliğine sahip konformasyonundaki tüm ipliklerinin birbirinden ayrıldığı ve böylece düzenli istif yapısının bozulduğu söylenebilir. Burada, D290V mutasyon sistemine ait simülasyonların RMSD değerlerindeki düşük ve kararlı (az değişen) değerler ise dikkat çekicidir. D290V sistemine ait ilk simülasyonunun ortalama RMSD değerlerinin $\sim 0.45 \mathrm{~nm}$ ikinci simülasyonun ise $\sim 0.51 \mathrm{~nm}$ civarında olduğu gözlemlenmektedir.

Çalışmamızda ele aldığımız WT ve D290V fibril sistemlerin konformasyonlarındaki değişimler üzerine yapılan araştırmamızı derinleştirebilmek adına, ikinci olarak Rg (jirasyon yarıçapı: Radius of gyration) analizi yapılmıştır. Rg analizi proteini oluşturan atomlar ile proteinin kütle merkezi arasındaki uzaklıkların simülasyonlar boyunca değişimlerinin bir ölçüsüdür. Başka bir ifadeyle Rg analizi ile protein konformasyonunun boyutlarındaki değişimleri simülasyonlar boyunca gözlemlemeye olanak sağlar. Şekil 3 WT ve D290V sistemleri için Rg değerlerinin simülasyonlar boyunca değişimlerini göstermektedir. Şekil 3 incelendiğinde Rg değerlerinin simülasyonlar boyunca değişim davranışlarının RMSD değerlerinde elde edilen davranış eğilimine benzer olduğu görülmektedir. Literatüre göre Rg değerlerindeki artış protein yapısındaki genişlemeye azalma ise protein konformasyonundaki büzüşmeye karş1lık gelmektedir (Lobanov ve ark., 2008). Özellikle WT sistemi için elde edilen önemli derecede yüksek değerler bu sistemdeki fibril ipliklerinin birbirinden uzaklaştığının açık bir göstergesidir. RMSD ve Rg analizleri sonucunda elde edilen bulgular birlikte değerlendirildiğinde, ele alınan fibril polimorfu için D290V mutant fibril sistemi kararlı konformasyonlara sahip iken WT 
konformasyonun bu polimorf yapısında var olamayacağı söylenebilir. Dolayısıyla ilgilenilen polimorf yapısı için yalnızca D290V mutant sistemin ilaç hedef yapısı olarak ele alınabileceğini sonucu çıkarılabilir.

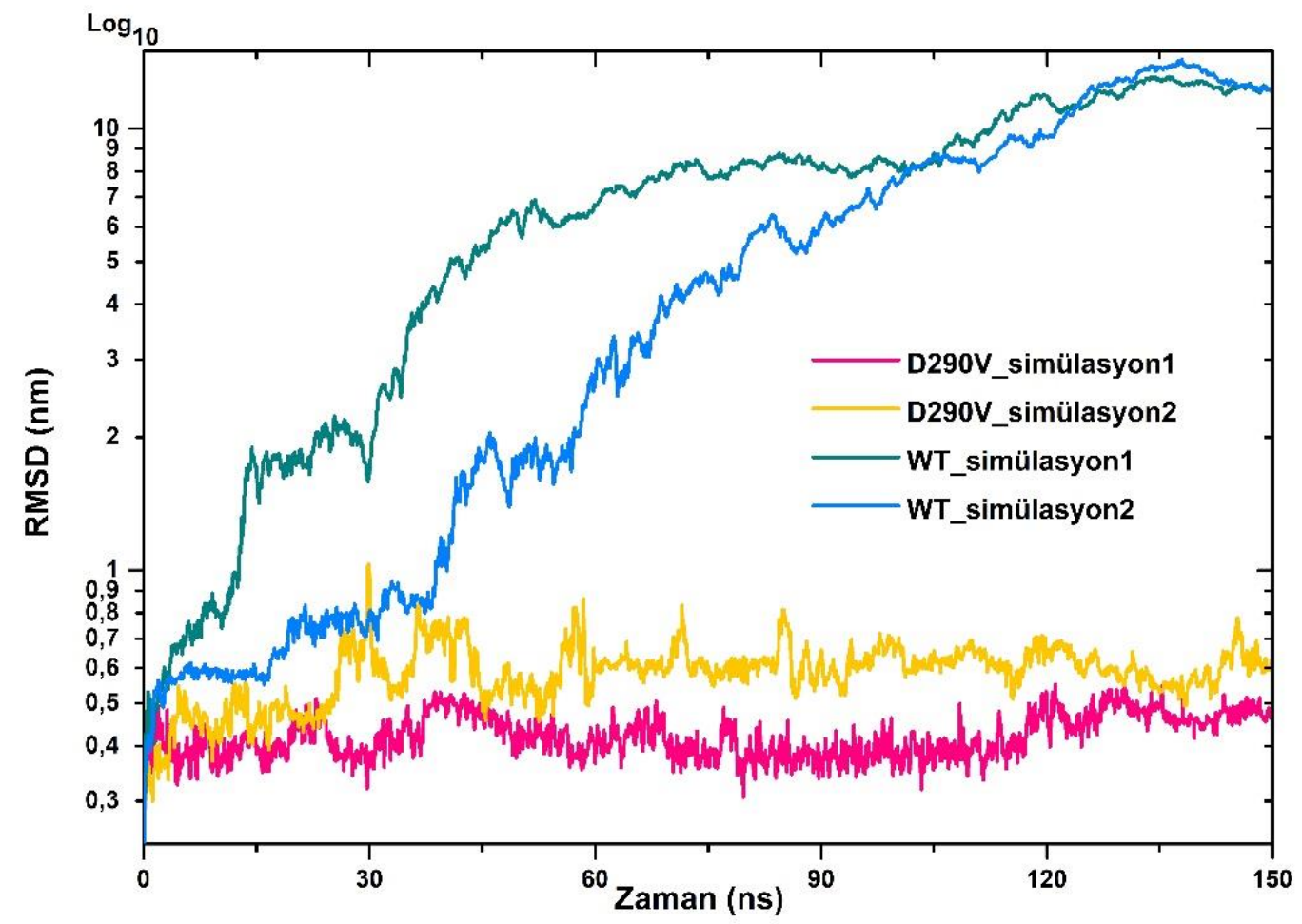

Şekil 2. hnRNPA2'nın LC(286-291) domain WT fibrili ve onun D290V mutasyonlu fibril yapıları için gerçekleştirilen 150ns'lik simülasyonlar boyunca RMSD değerlerinin değişimi

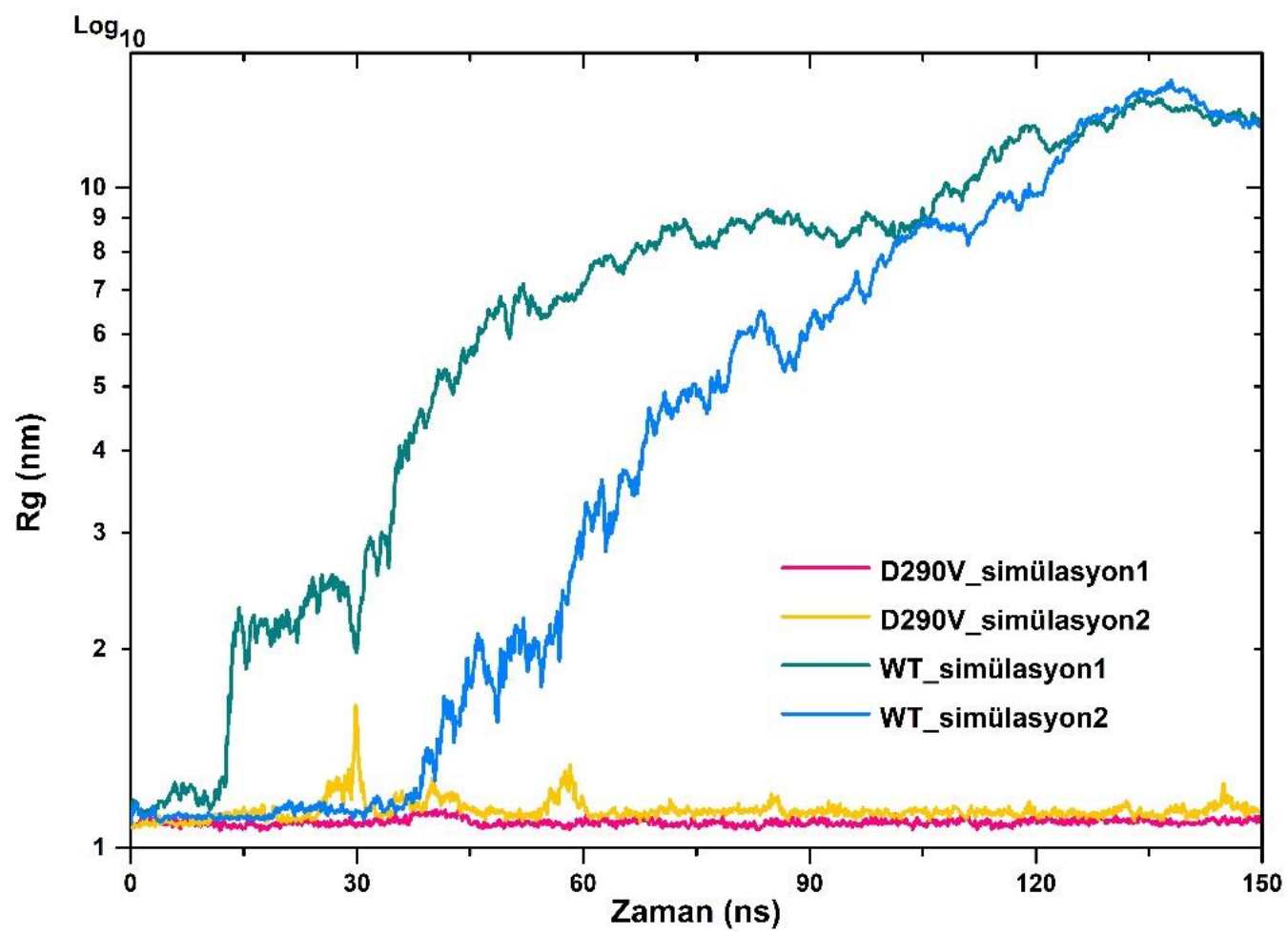

Şekil 3. hnRNPA2'nın LC(286-291) domain WT fibrili ve onun D290V mutasyonlu fibril yapıları için gerçekleştirilen 150ns'lik simülasyonlar boyunca Rg değerlerinin değişimi 
Ayrıca RMSD ve Rg analizlerinden elde edilen bulguların daha iyi özümsenebilmesi için fibril sistemlerinin 150ns'lik simülasyonlarının sonundaki 3B konformasyonlarının bir görselleştirilmesi Şekil 4'de sergilenmiştir. Şekil incelendiğinde D290V sisteminin konformasyonel kararlığını her iki simülasyonu için de büyük ölçüde koruduğu söylenebilir. Ancak yine de D290V sistemi içinde bazı ipliklerin doğal konformasyonel konumlarını bir miktar kaybettiği gözlemlenmektedir. Öte yandan WT sistemi için gerçekleştirilen her iki simülasyonun sonunda fibril ipliklerinin birbirinden ayrılarak uzaklaştığı ise açıkça görülmektedir.

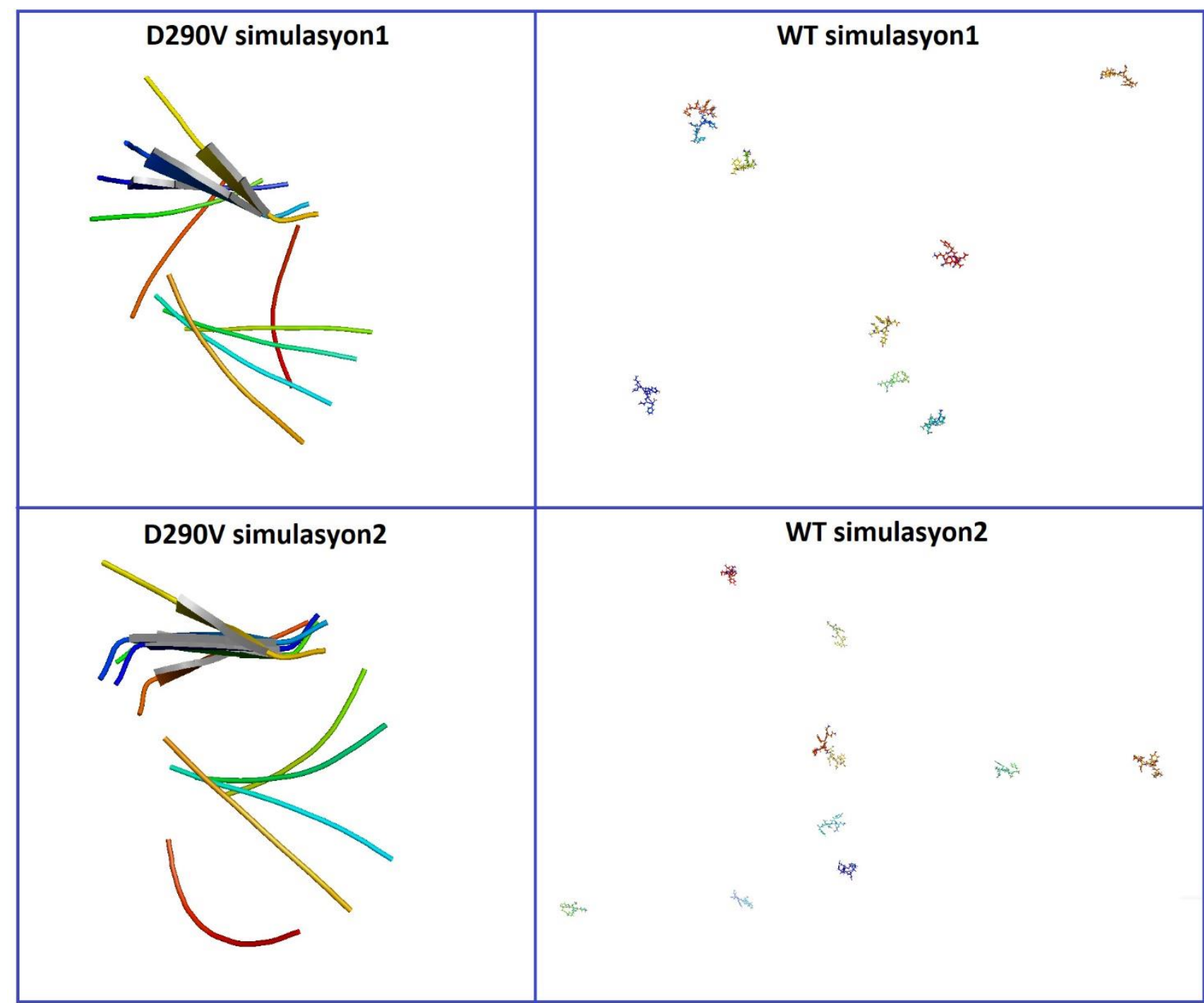

Şekil 4. hnRNPA2'nın LC(286-291) domain WT fibrili ve onun D290V mutasyonlu fibril yapıları için gerçekleştirilen 150ns'lik simülasyonların sonundaki anlık 3B görüntüleri

Ayrıca fibril konformasyonlarındaki düzenli istifli yapılardaki bozulmaların hangi ipliklerde daha önce başladığını ve hangi fibril ipliğinde daha fazla bozulma meydana geldiğini tespit edebilmek büyük önem arz etmektedir. Bu amaç doğrultusunda fibril sistemlerinin her bir ipliği için ayrı ayrı aminoasit başına RMSF (kök ortalama kare dalgalanma: root mean square fluctations) analizleri yapılmıştır. RMSF analizleri protein yapısındaki her bir aminoasitin doğal konumlarının simülasyonlar boyunca ortalama olarak değişimlerinin bir ölçüsü olup bu analiz sayesinde fibril konformasyonlarının kararlılığının bölgesel (lokal) olarak değerlendirilebilmesi mümkündür. Bu bağlamda, ilk olarak fibril sistemlerindeki düzenli istif yapısındaki bozulmaların hangi fibril ipliklerinde meydana geldiğinin tespit edilebilmesi için aminoasit başına RMSF değerleri her bir iplik için birbirinden bağımsız olarak Şekil 5'de 
sergilenmiştir. Şekil incelendiğinde WT sistemi için elde edilen yüksek değerler diğer analizlerde olduğu gibi yapıdaki ipliklerin birbirinden ayrıldı̆̆ını göstermektedir. D290V mutant sistemine odaklanıldığında her bir yaprağın en üstündeki ve en altındaki bölgelerde bulunan (bakınız Şekil 1: yaprak 1 için iplik A, E ve yaprak 2 için iplik F, J) fibril ipliklerinin her bir yaprağın merkez bölgelerinde bulunan fibril ipliklerine göre daha yüksek değerlere sahip olduğu görülmektedir. D290V sistemi için gözlemlenen düzenli istif yapılarındaki bozulmaların uç bölgedeki fibril ipliklerinden başlaması durumu aslında beklenilen bir sonuç olup literatürde bir Alzhemier hastalık fibrili için de benzer davranış eğilimi gözlemlenmiştir (Xi ve Hansmann, 2017). Çünkü bu ipliklerin bir yüzü, merkezdeki ipliklere göre çözeltiyle daha fazla temas halindedir ve iplikleri bir arada tutan atomik etkileşimlere daha az maruz kalmaktadır. Ayrıca, D290V sistemi için elde edilen simülasyon sonundaki 3B görüntülerden de bozulmanın bu uç kısımlarda bulunan ipliklerden başladığını rahatlıkla görülebilir.

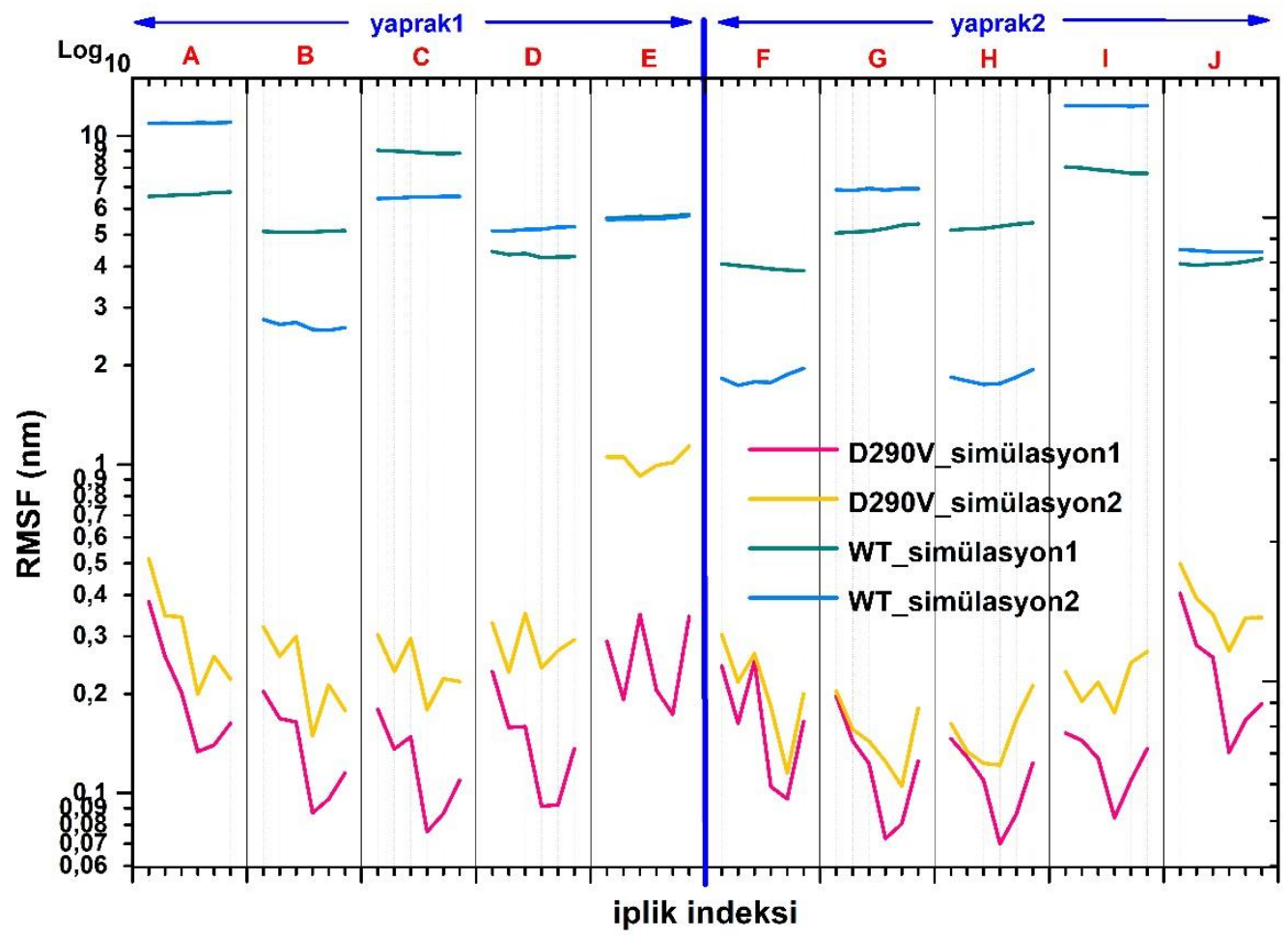

Şekil 5. hnRNPA2'nın LC(286-291) domain WT fibrili ve onun D290V mutasyonlu fibril yapılarındaki her bir ipliğin ayrı ayrı RMSF değerleri

Daha sonra konformasyonel değişimleri aminoasit bazında inceleyebilmek için her bir aminoasitin on iplik için elde edilen RMSF değerlerinin ortalaması Şekil 6'da sergilenmiştir. Bu analiz sayesinde ilgilenilen fibril yapılarının konformasyonel değişimlerine, aminoasit pozisyonlarının katkılarını değerlendirmek mümkün olacaktır. Diğer analizlerin sonuçlarında olduğu gibi WT sistemi yüksek değerlere sahiptir ve dolayısıyla bu sistem için bu RMSF analizlerinden de bir sonuç çıarmak çok mümkün değildir. D290V sistemi değerlendirildiğinde ise bu sistemin her iki simülasyonda da aminoasitlerin benzer dinamik bir davranışı sergilediği söylenebilir. Fibril yapraklarının terminal aminoasitleri olan Gly286 ve Phe291'nin diğer aminoasitlere kıyasla bir miktar yüksek sonuçları vermesi bu bölgelerin daha esnek olmasına atfedilmiş olup literatürdeki trend raporu ile uyumludur (Zheng ve ark., 2006). Öte yandan, tamamı fibril tabakaları arasında kalan ve karşılıklı tabakalar arası etkileşime sahip olan Asn289 ve Val290 aminoasitlerinin (bakınız Şekil 1) en düşük değerlere sahip olduğu görülmektedir. Bu türden kararlı konformasyona sahip fibril yapılarının çözeltiye daha az temas 
halinde olan fibril merkezi (core) bölgelerinin düşük değerler vermesi beklenilen bir sonuç olup literatürde farklı hastalıklar için tespit edilmiş fibril yapılarının simülasyon sonuçları ile tutarlıdır (Berhanu ve ark., 2012; Demir ve ark., 2018). Öte yandan, WT sisteminin 290. aminoasit pozisyonunda bulunan negatif yüklü Asp aminoasidinin sahip olduğu elektrostatik etkileşimlerin yaprak tabakaları arasında olumsuz bir etkiye sahip olma ihtimalinin çok yüksek olduğu sonucu çıkarılabilir ki yüklü aminoasitlerin fibril tabakaları üzerindeki bu türden olumsuz etkileri literatürde daha önceden rapor edilmiştir (Alıcı, 2020). Ayrıca fibril tabakaları üzerindeki faklı mutasyonların fibril yapılarını farklı polimorflara indükleyebileceği rapor edilmiştir (Fitzpatrick ve ark., 2013; Alred ve ark., 2014). Özetle yapılan tüm analizler sonucunda elde edilen bilgiler ışında WT'nin farklı bir şekillenime sahip fibril polimorf yapısında bulunacağı açıktır.

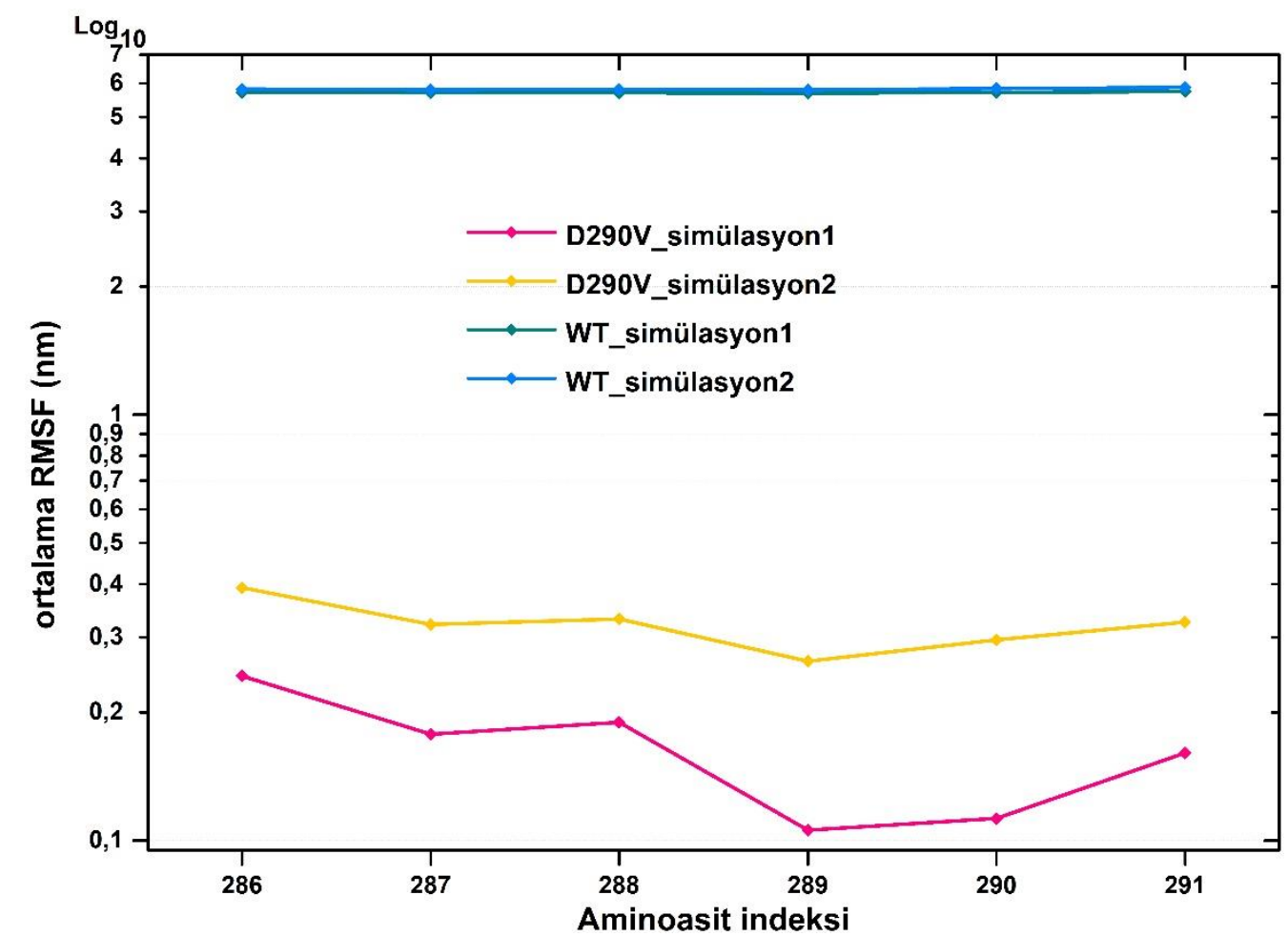

Şekil 6. hnRNPA2'nın LC(286-291) domain WT fibrili ve onun D290V mutasyonlu fibril yapılarındaki her bir aminoasidinin ortalama RMSF değerleri

\section{SONUÇ}

Bu çalışmada kristal yapısı çok yakın zamanda çözülmüş olan HnRNPA2'nın LC domaininin 286291 aminoasit dizilimini içeren bir fibril polimorf yapısı ele alınmıştır (Pdb kod: 6WPQ). Bu polimorf için D290V mutasyonunu içeren fibril yapısı ve mutasyonsuz vahşi tipteki fibril formunun yapısal özelliklerini ve kararlığını araştırmak için MD simülasyon yöntemi kullanılmıştır. Simülasyon sonuçlarına göre, D290V yapısına sahip fibril formunun ilgili polimorf için kararlı, vahşi tipin ise kararsız bir konfigürasyona sahip olduğu, dolayısıyla bu fibril polimorfu için yalnızca D290V mutasyonlu fibril konformasyonun gelecek ilaç çalışmaları için hedef yap1 olabileceği söylenebilir. Ayrıca, D290V yapısındaki düzenli istiflenmiş fibril yapısındaki bozulmaların her bir yaprak tabakasındaki beş ipliğin en üst ve alttaki ipliklerinden başladığı gözlemlenmiştir. Dahası, RMSF sonuçlarına göre D290V mutasyonundaki Asn289 ve Val290 aminoasitlerinin yüksek bölgesel kararlılıkları fibril bütünlüğünün korunmasında önemli rol oynadığı tespit edilmiştir. 
Simulasyonlar sonucunda elde edilen tüm bulgularımızın literatür ile büyük uyum gösterdiği söylenebilir. Sonuç olarak çalışmamızın bulgularının, HnRNPA2'nın LC domaininin farklı fibril polimorf yapılarını hedef alacak gelecekteki muhtemel ilaç tasarım çalışmaları için anahtarlar önseziler sağlamasını umut etmekteyiz.

\section{TEŞEKKÜR}

Bu çalışmaya 2015-22794455-03 nolu Altyapı Projesi ile maddi kaynak sağlayan Zonguldak Bülent Ecevit Üniversitesi Bilimsel Araştırmalar Proje Birimi’ne teşekkür ederiz.

\section{Çıkar Çatışması}

Makaleye ait çalışmanın planlanması, yürütülmesi ve makalenin yazılması aşamalarında herhangi bir çıkar çatışması olmadığını beyan ederim.

\section{Yazar Katkısı}

Makalenin planlanması, yürütülmesi ve yazılması makale tek yazarı olarak tarafımca yapıldı̆̆ beyan ederim.

\section{KAYNAKLAR}

Abraham MJ, Murtola T, Schulz R, Páll S, Smith JC, Hess B, Lindahl E, 2015. Gromacs: High Performance Molecular Simulations through Multi-Level Parallelism from Laptops to Supercomputers. SoftwareX, 1-2: 19-25.

Alıcı H, Karacaoğlan V, Demir K, 2018. İnsan Kemokin Reseptörü CXCR3'ün N-Terminal Bölgesinin Moleküler Dinamik Simülasyon Yöntemi ile Modellenmesi ve Yapısal Analizi. Karaelmas Fen ve Mühendislik Dergisi, 8 (2): 606-614.

Alic1 H, 2020. In Silico Analysis: Structural Insights About Inter-Protofilaments Interactions for A-Synuclein (50-57) Fibrils and its Familial Mutation. Molecular Simulation, 46 (12): 867-878.

Alred EJ, Scheele EG, Berhanu WM, Hansmann UH, 2014. Stability of Iowa Mutant and Wild Type A B-Peptide Aggregates. The Journal of Chemical Physics, 141 (17): 175101.

Amaya J, Ryan VH, Fawzi NL, 2018. The Sh3 Domain of Fyn Kinase Interacts with and Induces Liquid-Liquid Phase Separation of the Low-Complexity Domain of Hnrnpa2. The Journal of Biological Chemistry, 293 (51): 1952219531.

Berhanu WM, Hansmann UH, 2012. Side-chain Hydrophobicity and the Stability of Aß16-22 Aggregates. Protein Science, 21 (12): 1837-1848.

Burd CG, Dreyfuss G, 1994. Rna Binding Specificity of Hnrnp A1: Significance of Hnrnp A1 High-Affinity Binding Sites in Pre-Mrna Splicing. The EMBO Journal, 13 (5): 1197-1204.

Bussi G, Donadio D, Parrinello M, 2007. Canonical Sampling through Velocity Rescaling. The Journal of Chemical Physics, 126 (1): 014101.

Darden T, York D, Pedersen L, 1993. Particle Mesh Ewald: An N·Log(N) Method for Ewald Sums in Large Systems. The Journal of Chemical Physics, 98 (12): 10089-10092.

DeLano WL, 2002. Pymol: An Open-Source Molecular Graphics Tool. CCP4 Newsletter on protein crystallography, 40 (1): 82-92.

Demir K, Alıcı H, Yaşar F, 2018. Conformational Stability of the Tetrameric De Novo Designed Hexcoil-Ala Helical Bundle. Chinese Journal of Physics, 56 (1); 46-57.

Duan Y, Du A, Gu J, Duan G, Wang C, Gui X, Ma Z, Qian B, Deng X, Zhang K, Sun L, Tian K, Zhang Y, Jiang H, Liu C, Fang Y, 2019. Parylation Regulates Stress Granule Dynamics, Phase Separation, and Neurotoxicity of Disease-Related Rna-Binding Proteins. Cell Research, 29 (3): 233-247.

Essmann U, Perera L, Berkowitz ML, Darden T, Lee H, Pedersen LG, 1995. A Smooth Particle Mesh Ewald Method. The Journal of Chemical Physics, 103 (19): 8577-8593.

Fitzpatrick, AW, Debelouchina GT, Bayro MJ, Clare DK, Caporini MA, Bajaj VS, MacPhee CE, 2013. Atomic Structure and Hierarchical Assembly of a Cross- $\beta$ Amyloid Fibril. Proceedings of the National Academy of Sciences, 110 (14): 5468-5473. 
Gilks N, Kedersha N, Ayodele M, Shen L, Stoecklin G, Dember LM, Anderson P, 2004. Stress Granule Assembly Is Mediated by Prion-Like Aggregation of Tia-1. Molecular Biology of The Cell, 15 (12): 5383-5398.

Gomes E, Shorter J, 2019. The Molecular Language of Membraneless Organelles. The Journal of Biological Chemistry, 294 (18): 7115-7127.

Gui X, Luo F, Li Y, Zhou H, Qin Z, Liu Z, Gu J, Xie M, Zhao K, Dai B, Shin WS, He J, He L, Jiang L, Zhao M, Sun B, Li X, Liu C, Li D, 2019. Structural Basis for Reversible Amyloids of Hnrnpa1 Elucidates Their Role in Stress Granule Assembly. Nature Communications, 10 (1): 2006.

Guil S, Cáceres JF, 2007. The Multifunctional Rna-Binding Protein Hnrnp A1 Is Required for Processing of Mir-18a. Nature Structural \& Molecular Biology, 14 (7): 591-596.

Huang J, Rauscher S, Nawrocki G, Ran T, Feig M, de Groot BL, Grubmüller H, MacKerell AD, 2017. Charmm36m: An Improved Force Field for Folded and Intrinsically Disordered Proteins. Nature Methods, 14 (1): 71-73.

Jain N, Lin H-C, Morgan CE, Harris ME, Tolbert BS, 2017. Rules of Rna Specificity of Hnrnp A1 Revealed by Global and Quantitative Analysis of Its Affinity Distribution. Proceedings of the National Academy of Sciences of the United States of America, 114 (9): 2206-2211.

Jean-Philippe J, Paz S, Caputi M, 2013. Hnrnp A1: The Swiss Army Knife of Gene Expression. International Journal of Molecular Sciences, 14 (9): 18999-19024.

Jorgensen WL, Chandrasekhar J, Madura JD, Impey RW, Klein ML, 1983. Comparison of Simple Potential Functions for Simulating Liquid Water. The Journal of Chemical Physics, 79 (2): 926-935.

Kato M, Han Tina W, Xie S, Shi K, Du X, Wu Leeju C, Mirzaei H, Goldsmith Elizabeth J, Longgood J, Pei J, Grishin Nick V, Frantz Douglas E, Schneider Jay W, Chen S, Li L, Sawaya Michael R, Eisenberg D, Tycko R, McKnight Steven L, 2012. Cell-Free Formation of Rna Granules: Low Complexity Sequence Domains Form Dynamic Fibers within Hydrogels. Cell, 149 (4): 753-767.

Kim HJ, Kim NC, Wang Y-D, Scarborough EA, Moore J, Diaz Z, MacLea KS, Freibaum B, Li S, Molliex A, Kanagaraj AP, Carter R, Boylan KB, Wojtas AM, Rademakers R, Pinkus JL, Greenberg SA, Trojanowski JQ, Traynor BJ, Smith BN, Topp S, Gkazi A-S, Miller J, Shaw CE, Kottlors M, Kirschner J, Pestronk A, Li YR, Ford AF, Gitler AD, Benatar M, King OD, Kimonis VE, Ross ED, Weihl CC, Shorter J, Taylor JP, 2013. Mutations in PrionLike Domains in Hnrnpa2b1 and Hnrnpa1 Cause Multisystem Proteinopathy and Als. Nature, 495 (7442): 467473.

Lobanov MY, Bogatyreva NS, Galzitskaya OV, 2008. Radius of Gyration as an Indicator of Protein Structure Compactness. Molecular Biology, 42 (4): 623-628.

Lu J, Cao Q, Hughes MP, Sawaya MR, Boyer DR, Cascio D, Eisenberg DS, 2020. Cryoem Structure of the LowComplexity Domain of Hnrnpa2 and Its Conversion to Pathogenic Amyloid. Nature Communications, 11 (1): 4090-4090.

Molliex A, Temirov J, Lee J, Coughlin M, Kanagaraj AP, Kim HJ, Mittag T, Taylor JP, 2015. Phase Separation by Low Complexity Domains Promotes Stress Granule Assembly and Drives Pathological Fibrillization. Cell, 163 (1): 123-133.

Parrinello M, Rahman A, 1981. Polymorphic Transitions in Single Crystals: A New Molecular Dynamics Method. Journal of Applied Physics, 52 (12): 7182-7190.

Purice MD, Taylor JP, 2018. Linking Hnrnp Function to Als and Ftd Pathology. Frontiers in Neuroscience, 12: 326326.

White R, Gonsior C, Krämer-Albers E-M, Stöhr N, Hüttelmaier S, Trotter J, 2008. Activation of Oligodendroglial Fyn Kinase Enhances Translation of Mrnas Transported in Hnrnp A2-Dependent Rna Granules. The Journal of Cell Biology, 181 (4): 579-586.

Xi W, Hansmann UH, 2017. Ring-like N-fold Models of A $\beta 42$ Fibrils. Scientific Reports, 7 (1): 1-14.

Xiang S, Kato M, Wu LC, Lin Y, Ding M, Zhang Y, Yu Y, McKnight SL, 2015. The Lc Domain of Hnrnpa2 Adopts Similar Conformations in Hydrogel Polymers, Liquid-Like Droplets, and Nuclei. Cell, 163 (4): 829-839.

Zheng J, Ma B, Tsai CJ, Nussinov R, 2006. Structural Stability and Dynamics of an Amyloid-forming Peptide GNNQQNY from the Yeast Prion Sup-35. Biophysical Journal, 91 (3): 824-833. 